This report is generally cautious in its recommendations and must be seen as a call for further scientific and ethical reflection in an area where the public perception of the welfare of animals is in a state of transition.

DAVID LAMB University of Birmingham

\section{Who Should We Treat? Law, Patients and Resources in the NHS}

\author{
Christopher Newdick, Oxford, \\ Clarendon Press, 1995, 323 pages, \\ $£ 15.99$.
}

The problem in writing about the issues facing the National Health Service (NHS) is the rapid pace of change that the service continues to undergo. The debate about rationing, when linked to practice, is no exception. The rapid changes of the NHS pose authors with the problem of needing to describe structures which are rapidly out of date. This is only partly overcome by Newdick in Who Should We Treat?, an account of the difficulties and dilemmas faced by all levels of the NHS as decisions are made about who should receive treatment and the legal challenges these pose.

The first chapter sets the scene by sketching out the issues. Newdick discusses the belief current at the start of the NHS that its creation would diminish the need for health care by reducing the incidence of ill-health in society: a belief since confounded by the growth of medical knowledge and the expanding demand for health care, the growing numbers of elderly people in the population, the costs of medical litigation and the difficulty of determining priorities when there is no nationally agreed framework. This is set against a background where "we need to remind ourselves that good health and a good health service may have very little in common".

This introductory first chapter provides a good summary of these wellknown themes, as does the next section, which sketches out the economic principles of rationing and makes reference to international experiences of rationing, including the well-publicised Oregon experiment.

From the models of rationing the text moves to the dilemmas which arise from managed competition, a compromise on the market philosophy on which the NHS reforms were based and discusses some of the changes and paradoxes that have occurred since the introduction of the internal market. Readers involved in day-to-day decisions about which patients to treat will find that the dilemmas and confusions resonate with their own experiences: the efficiency trap, for example, where efficient hospitals "will face the prospect of exhausting their revenue before the end of the financial year because the money available to purchasers remains limited"; or while "money follows patients" was the intention, purchasers in effect make decisions about the money available, which determines where patients may be treated. The limitations of a market philosophy on the NHS are made evident. The lack of information on clinical outcomes; the lack of a national strategy to balance the competing demands of both local services and centres of excellence at the forefront of medical technology, and the inherent inequalities created by GP fundholding all constrain the market place. Thus, despite the desirability of equality it is not a legal entitlement and these factors all contribute to the inevitability of tiers of health care as GPs, health authorities and trusts strive to fulfil different objectives.

The section on private hospitals discusses another difficulty consequent on the NHS Act. If purchasers can get a better short-term deal from a local private hospital, revenue to the NHS will decline. But what of the impact on other functions of the NHS, such as education and research and what of the impact of funding short term acute care rather than long term care for chronic conditions not funded by private insurance? The theme of discomfort caused by the apposition of public and private sectors is again reflected in the debate on accountability, for example, who would be negligent if a patient were poisoned by food from a private caterer or for an error in treatment from a consultant contracted by a fundholder? Because of the pace of structural changes the law is unsettled on these issues, as it is on the legal status of contracts.

The chapter on the regulation of standards discusses rationing and the legal issues which arise because of scarcity. Improved levels of care could obviously be achieved if more resources were available, but in the foreseeable future more has to be achieved with relatively less, and the author asks what are the implications for quality of care and what is the liability of the clinician who makes the decisions. It will be reassuring to those in health authorities and trusts that the theory of primary liability recognises that difficult choices have to be made, and this point is developed well, linked to a fascinating debate around excusable and inexcusable differences of opinion. This chapter raises a theme which recurs throughout the book: that of the power of clinicians in decision-making and the impact of the reforms, with the increase in managerialism, on that power. Linked to this theme is that of professional self-regulation with the development of guidelines and audit. The examples given in the chapter on statutory regulation of standards would seem to suggest that judges are reluctant to become involved in assessment of priorities and the allocation of health service resources. The Wednesbury principle applies in most circumstances: that decisions concerning the allocation of resources should always give proper weight to the clinical advice of doctors and not be restricted to the financial advice of accountants. Such self-regulation is increasingly important but may lead to conflict between the interests of patients and those of managers. Questions of accountability and of complaints are discussed within the context of the law but the structural changes detract from this section of the book.

Overall the book is at its best when dealing with the complex issue of who should be treated and tying this to legal precedent. It provides insight into the complexity of the relationship between clinicians and legal precedents on which judgments are made. It is perhaps over-ambitious in trying to describe all the structures and changes faced within the health service and shows less understanding of the issues in primary care. This is compounded by the inaccuracies in describing the existing NHS. Despite this, the breadth of the text is to be praised and the tensions between the law, patients and resources in the NHS are well described. This book can be recommended to anyone interested in dealing with the practical challenges of rationing resources within the NHS.

SIAN GRIFFITHS

Oxfordshire Health Authority, Richards Building,

Old Road, Headington, Oxford $O X 37 L G$ 